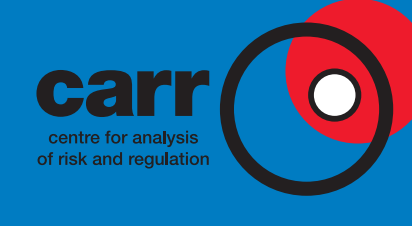

centre for analysis of risk and regulation An ESRC Research Centre

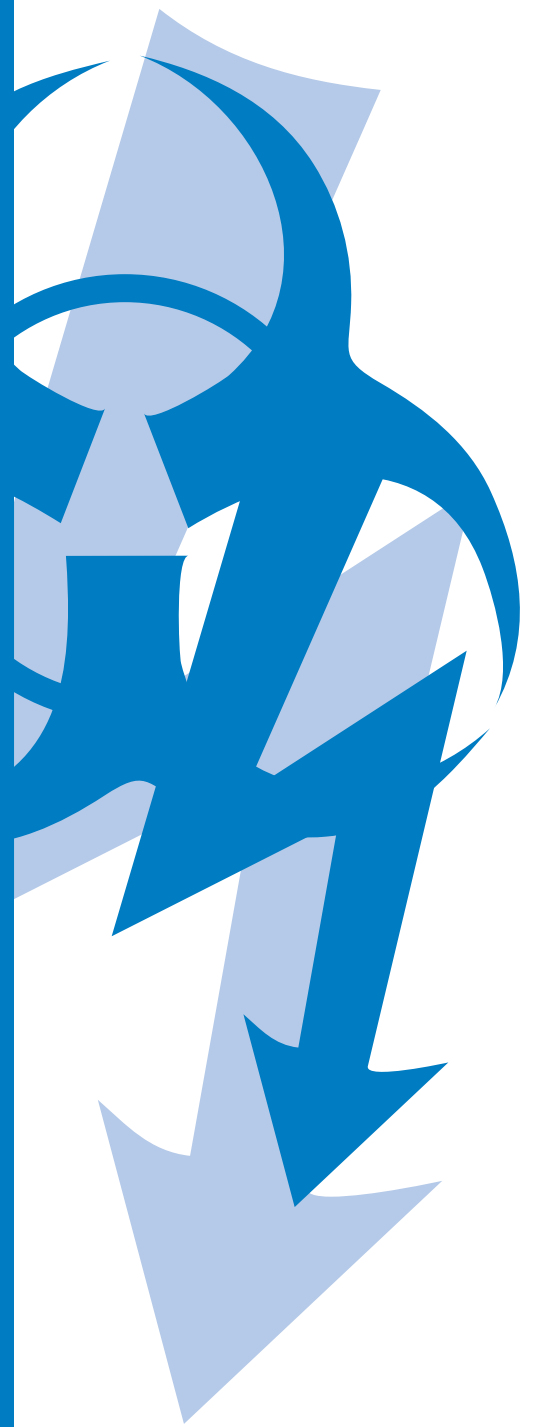

\title{
Building a Boundary Object: The Evolution of Financial Risk Management
}

\author{
Yuval Millo and \\ Donald Mackenzie
}




\title{
Building a Boundary Object: The Evolution of Financial Risk Management
}

\author{
Yuval Millo and Donald Mackenzie
}

\section{Contents}

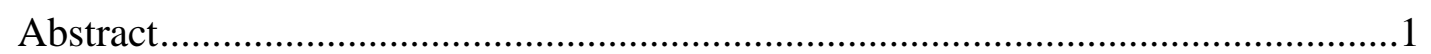

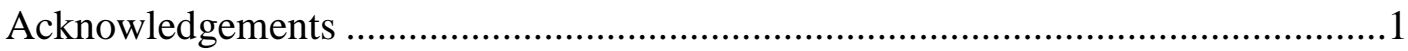

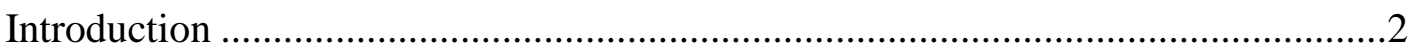

Financial risk management and boundary objects ................................................

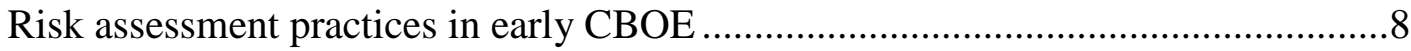

The use of Black's sheets .................................................................

Comprehensive risk management systems …..................................................... 10

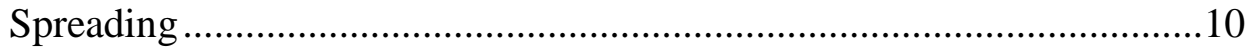

Multi-exchange option trading ......................................................11

Risk management away from the trading floor ....................................................13

Financial risk management and options clearing …..........................................17

Risk management and the 1987 market crash .................................................... 19

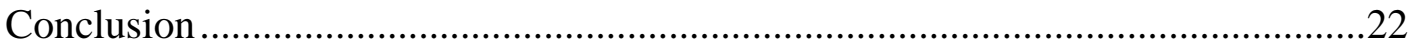

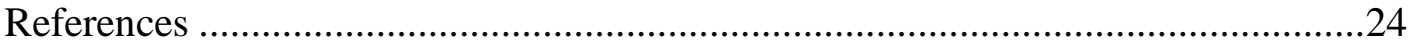


The support of the Economic and Social Research Council (ESRC) is gratefully acknowledged. The work was part of the programme of the ESRC Centre for Analysis of Risk and Regulation.

Published by the Centre for Analysis of Risk and Regulation at the London School of Economics and Political Science

Houghton Street

London WC2A $2 \mathrm{AE}$

UK

(C) London School of Economics and Political Science, 2007

ISBN 9780853281405

All rights reserved.

No part of this publication may be reproduced, stored in a retrieval system, or transmitted, in any form or by any means, without the prior permission in writing of the publisher, nor be otherwise circulated in any form of binding or cover other than that in which it is published and without a similar condition including this condition being imposed on the subsequent purchaser.

Printed and bound by Kube, December 2007 


\title{
Building a Boundary Object: The Evolution of Financial Risk Management
}

\author{
Yuval Millo and Donald Mackenzie ${ }^{1}$
}

\begin{abstract}
The paper traces the intertwined evolution of financial risk management and the financial derivatives markets. Spanning from the late 1960s to the early 1990s, this paper reveals the social, political and organizational factors that underpinned the exponential success of one of today's leading risk management methodologies, the applications based on the Black-Scholes-Merton options pricing model. Using empirical data collected from primary documents and interviews, the paper argues that the remarkable success of today's financial risk management should be attributed primarily to the communicative and organizational aspects of the methods rather than to their accuracy or validity. The analysis claims that financial risk management became a boundary object - a set of instructions and practices that served as a common ground and as a basis for discussion and operation despite having quite different meanings to the different communities of practice involved. As risk management became an integral part of common organizational market practices (e.g. margin calculation and intra-portfolio coordination) the actual content of the predictions that risk management systems produced became less relevant. In fact, a seemingly paradoxical shift took place: as the consensus around risk management systems was established, the accuracy and validity of the predictions produced by them became less important.
\end{abstract}

\section{Acknowledgements}

The authors thank Daniel Beunza, Asaf Dar, Stephen Dunne, Manu Haven, Peter Levin, Geoff Lightfoot, Simon Lilley, Roi Livne, Andrea Mennicken, Peter Miller, Fabrizio Panozzo, Martin Parker, Mike Power, Alex Preda, Nick Prior, Uri Schweid, David Stark, Balázs Vedres, Dani Vos, Josh Whitford, Yuval Yonay and Ezra Zuckerman for their helpful comments. We also thank participants in seminars at the London School of Economics, University of Edinburgh, Università Ca' Foscari, Columbia University, University of Haifa and University of Leicester where earlier versions of this paper were presented. We would also like to thank the anonymous CARR referees. Special thanks go to Amy Greenwood for her precise and swift editing. All remaining mistakes are, of course, ours.

1 Correspondence: Yuval Millo, Department of Accounting, London School of Economics and Political Science, Houghton Street, London WC2A 2AE. (y.millo@lse.ac.uk). 


\section{Introduction}

Financial risk management has become a ubiquitous feature of financial markets, but nowhere more so than in the markets for financial derivatives. The connection between financial risk management and financial derivatives is both conceptual and historical. The link between the two is conceptual because financial derivatives have been envisioned and introduced as market-based risk management tools, aimed at distributing risk among market participants. Financial derivatives allow those who wish to reduce the risk embedded in their market positions and to transfer it (i.e. sell it) to others who are interested in bearing more risk, in expectation for increased return. Derivatives contracts are designed to capture, quantify and trade risks embedded into a variety of phenomena. In effect, financial derivatives market are markets for risk, as risk is defined, qualified, packaged and re-distributed in these markets. The link between contemporary financial risk management and financial derivatives is also historical. The derivative market on which this paper is focused, the first organized exchange for the trading of financial derivatives, was also the focal point around which one of today's leading financial risk management methodologies developed. The American stock options exchange, the Chicago Board Options Exchange (CBOE), was a 'natural laboratory' where the option pricing models of Black and Scholes (1972, 1973) and Merton (1973) were tested. ${ }^{2}$

If, as the conceptual and historical links imply, financial risk management and financial derivatives are twins, born and raised in the same metaphorical household (the derivatives exchanges) then how should we understand their spectacular growth? In a recent book about the evolution of risk management, Michael Power (2007) traces the evolution of risk management as an organizational phenomenon. Power claims that the explosive growth of risk management in the last two decades is related to a gradual convergence between risk calculation and risk management. This historical process eventually led to a subsuming of the former into the latter. That is, nowadays risk is regarded as a manageable factor rather than merely a measurable, quantifiable and calculable entity. In other words, risk has been 'internalized'. Organizations re-positioned themselves vis-à-vis risk; they moved from being spectators at an external phenomenon to managers of an increasingly inherent corporate resources.

This paper explores and analyzes one of the important starting points in this process: the evolution of financial risk management in derivatives exchanges. The growth of financial risk management is underpinned by the transformation undergone by risk assessment techniques. Mathematical 'price finders', trading aides for the individual trader, were transformed into institutionalized and indispensable managerial coordination tools. This phenomenon in itself deserves sociological and historical analysis. Yet, within this general historical trend, a more subtle institutional change was taking shape. As risk management turned into an integral part of common organizational market practices (e.g. margin calculation and intra-portfolio coordination), the actual content of the predictions that risk management systems produced became less and less relevant. In fact, a seemingly paradoxical shift was taking place: as the consensus evolving around management systems established, the accuracy and validity of the predictions produced by them became less important.

2 For a detailed account of the interdependency between the evolution of the options market and the economic model see: MacKenzie \& Millo 2003; MacKenzie 2006. 


\section{Financial risk management and boundary objects}

In the last ten years, we witnessed a growing interest in the social and institutional dimensions of financial markets and their structure and operation (Baker, 1984; Abolafia, 1996; Zuckerman, 1999; MacKenzie 2001; Brügger \& Knorr-Cetina, 2002; MacKenzie \& Millo 2003; Beunza \& Stark 2004). Yet, apart from notable exceptions discussed in the paper, this interest in financial markets has so far not been expanded to the study of financial risk management and the evolution of this important techno-social institution. The emergence of risk management introduced new practices to the markets and contributed to the creation of interrelated communities of practice. Indeed, by focusing on the transformation from assessment of financial risk to financial risk management, we highlight a practice-related dimension of the historical process and its communicative aspects. The change in the risk-related practices from essentially calculative processes to managerial ones also entailed a transformation in the role of risk and risk predictions as a communicative medium. As risk management gradually became a central organizational praxis, risk-based communication and risk-based coordination emerged and crystallized.

To see how an analysis of financial risk management can enrich our understanding of cooperation in markets, we need to refer to previous works regarding coordination and co-operation in financial markets. Following Polanyi's work (Polanyi \& MacIver, 1957), one of Mark Granovetter's (1985, 1992) fundamental theoretical claims is that markets should be regarded as social constructions that evolve on the basis of pre-existing social and cultural frameworks, in which markets are 'embedded' and are not necessarily economic. Hence, the evolution of economic institutions takes place through continuous interactions among actors who hold a variety of motivations and worldviews. Granovetter's central concept - the embedding of markets in pre-existing sociocultural frameworks - focused on the resulting economic structures. Other economic sociologists such as Mitchell Abolafia (Abolafia, 1996), Wayne Baker (Baker, 1984) and Brian Uzzi (Uzzi, 1996; Uzzi \& Gillespie 2002; Uzzi \& Lancaster, 2003), who built upon Granovetter's theoretical perspective, studied the interaction of a variety of individual actors in financial markets. Abolafia's research about the New York Stock Exchange showed that the common view of the financial trading world as an atomistic, egoistic, profit-driven social environment was far from accurate. Market participants frequently created social networks and very seldom operated alone. These networks imposed unwritten (but carefully guarded) rules of reciprocity. For example, a trader who failed to 'give back a trade' (i.e. partake in a non-profitable exchange with a fellow trader who previously had done so for them) risked being excluded from the trade circles. Baker, who studied an options exchange, found that traders tended to operate within more or less a set network of trading associates. This stream of empirical works demonstrated persuasively that fundamental elements underpinning market behaviour are regulated through dense personal networks of crisscrossing favours and animosities, which then feed into equally elaborate sets of closely guarded norms.

In particular, the work on the embedding of social networks and their role in markets tells us that we need to look for a theoretical perspective that combines action and structure when we conceptualize the evolution of financial risk management, rather than a theoretical framework that traces primarily the 
formation of structures. When the 'embeddedness approach' is represented in terms of historical processes, two preliminary premises emerge. First, financial risk management did not evolve in a linear fashion, but rather in a network-like one. That is, the various market participants did not form an 'assembly line' where one actor operated after the other, each contributing to the final shape of the system. Instead, the evolution process unfolded through continuous simultaneous interactions without the presence of a meaningful command and control centre. Second, inherent to the interactive and networked nature of the historical evolutionary process is the heterogeneity of the actors involved. As they interact, the various market participants promote different, even conflicting, operative agendas, each rooted in a different worldview. Hence, the overall environment where financial risk management evolves should be regarded as a heterogeneous network.

Albeit being relevant to the development of a theoretical framework, interpersonal networks reveal only a partial picture of the story of financial risk management. First, the empirical research that followed the 'embeddedness approach' focused on collecting contemporaneous data (participant observation and quantitative analysis) from which the empirical conclusions were drawn. As useful as this approach is in revealing how inter-personal connections frame and configure economic ones, the longer-term processes of institutionalization by which patterns of network-based coordinated action become part of the market's infrastructure are not likely to be captured by such methodological tools. In contrast, the historical sociology perspective applied in this research, using both oral history methods (interviews) and primary documents, is geared towards the analysis of longer historical durations and assessing their impact on organizational structures. In fact, the empirical evidence and the historical analysis in the paper show that a 'snapshot' view of any one point in time during the twenty-year period analyzed in the paper could have led to mistaken conclusions about the way financial risk management evolved.

Another area where the 'embeddedness approach' can be enriched is by taking into account the role of non-human actors in the shaping of financial risk management. Financial markets are commonly described as an environment saturated in sophisticated technological artefacts. These are an indistinguishable part of today's financial market: printouts of calculations, display screens and trading floor workstations. However, less common is a realization of the part that technology plays in shaping the structure of markets. In a beautifully written paper, Kalthoff (2005) shows how practices that evolved around the use of computer software ('epistemic practices') crystallized institutional risk management routines. Kalthoff's findings reveal that practices did not emerge primarily from simple inter-personal interaction, but that coordinated communication was mediated by technical representations of risks and through that mediated representation risk management evolved and was established. A recent paper by Miller and O'Leary (2007) draws similar conclusions regarding the role that materiality played in the growing efficacy of capital budgeting. Miller and O'Leary argue persuasively that the efficacy of heterogeneous networks as agents of constitutive change is dependent on their 'intermediaries', the material content (e.g. written documents, technical artefacts, money) that circulates in the network and embodies, in effect, the connections among the actors. 
The hybrid human-machine networks through which financial risk management evolved is tightly related to the 'facticity' of risk management: the ability of risk management systems to produce results that would be perceived as valid and accurate descriptions of a reality (Latour, 1988). In a forthcoming book, Donald MacKenzie argues that the production of prices in financial markets is inherently embedded in the production of validity for those prices. That is, markets have to maintain the legitimacy of their prices as factual descriptions of the tradable values of the assets exchanged in the market. That ability, as the analysis below aims to show, is critically dependent on the creation and maintenance of a technology-driven, widely acceptable non-contextual set of descriptors. For example, a portfolio manager would find it difficult to trust the figures her risk management software produces if she believed that those figures were valid only for the specific set of circumstances in which they were produced. On the other hand, if the same portfolio manager had trusted that her risk management software 'speaks' in a universal language and thus her level of calculated risk is comparable with those of others who use the same risk methodology, then it would be easier for her to assign a high degree of validity to the results. It is true that such a detachment between the contextual (and less valid) and the universal (and therefore more valid) informational items can be created, hypothetically, without the presence of machine. Nonetheless, done manually, such a process would have practically paralyzed the market's activity. As the historical case shows repeatedly, inhuman speed and efficiency were the factors that kept the 'facts machine' of financial risk management running smoothly.

Referring to financial risk management as a set of institutionalized techno-social practices brings to the fore the communicative aspect of risk management. If, as Power claims, a major transformation has turned risk calculation into risk management then an empirical examination should reveal organizational actors that direct more resources to communicating and coordinating action using risk management and pay relatively less attention to calculating risk levels. This communicative aspect of risk management also has reflexive and constitutive implications. Risk management allows market participants to produce a map of risks and opportunities from which a plan of action could be derived. Naturally, any map, be it a geographical map or a risk map, is charted while incorporating a particular perspective. That is, an actor's point of view is the initial coordination according to which risks are defined and risk assessments are made. Therefore, the way an organizational actor depicts its risks is contingent upon how that actor perceives itself, its goals and its relationships with other actors. Consequently, since risk management is not only a description of a given reality but includes a prediction and is operated upon as a blueprint for action, it includes a constitutive (or performative) element. The way organizations depict their risks has a significant effect on the way they will react to events and to other actors. Over time, an influential risk management scheme (and, as we will see, financial risk management became significantly influential) will bring about institutionalized patterns of risk embodiment.

So far, we presented the analytical layout of how risk management can serve as a managerial tool. However, to theorize how financial risk management became such a dominant factor, our theoretical frameworks needs to be able to answer the following question: why did a particular risk methodology become successful while others did not? More specifically, can a general set of conditions be identified that would determine the likelihood of a particular financial risk 
management system becoming successful? A potential candidate for such a theoretical framework is the concept of boundary objects. The notion of boundary objects was used first by Leigh Star and Griesemer (1989) to describe artefacts, procedures, concepts or realms of knowledge that served as joint reference points accepted by different groups in spite of the fact that each group may have different cultures and beliefs, including radically different understandings of the objects in question. In a later publication, the influential book Sorting Things Out, Bowker and Leigh Star (1999) present a more general version of the boundary object concept and use it to analyze classificatory systems, trace the ways through which they were embedded into organizational infrastructures and eventually become part of the taken-for-granted organizational reality. Using detailed case studies, Bowker and Leigh Star describe how the networks of connections both within organizations and among them created and legitimized rules and practices; they define a boundary object as an object that can facilitate communication among 'several communities of practice and satisfy the informational requirements of each of them. Boundary objects are both plastic enough to adapt to local needs and constraints, yet robust enough to maintain a common identity across sites' (1999: 297).

This description fits remarkably well with the conditions that surrounded financial risk management in the early derivatives markets. There, the different market participants held widely varying perceptions with regard to risk, from which different needs and constraint were derived. Under such conditions, for a boundary object to serve as a basis for co-operative communication among the groups, it would have to include representations that correspond with the different perceptions. As we shall see, financial risk management evolved into such a 'plastic' representation, that it is able to accommodate the conflicting organizational demands while maintaining a common, universal 'risk language'. Schematically, there existed three types of market participants in the case: traders, regulators and clearing bodies, each holding a different set of conceptions, expertise and agendas to promote and consequently, each regarded financial risk differently from the others. For example, for the majority of traders, risk was manifested by adverse movement in prices. In contrast, the securities regulator saw risk as the possibility of brokers' customers suffering inadvertent losses because of their involvement in their broker's positions. Yet another perspective on risk was held by the clearinghouse; there, risk was embodied in the possibility that traders would not make good their part of the financial contracts - leaving the clearinghouse to pay.

The above examples point at several aspects where the case of financial risk management can enrich the existing concept of boundary objects. First, the commonly acceptable concepts related to financial risk management needed to include detailed instructions for the active management of risk. This requirement rules out as explanatory factors boundary objects of the 'lowest common denominator' type: objects that only describe, but do not offer a plan for action. Second, the strength of boundary objects in options market derived from the fact they provided each of the participants with a plan for risk management that suited their particular preferences. Third, because market activity demanded continuous use of risk management techniques, the efficiency of boundary objects was constantly tested. Again, the ability of risk management techniques to bridge over differences was tested each time a decision was made. 
The dynamic and iterative nature of financial markets calls for an expansion of the initial boundary object concept. Duncker and Disco (1998) and Duncker (2001) describe several stages in the development of a communicative medium in a setting of an interdisciplinary research project where the accuracy of the boundary objects (how well they 'translate' information from one expertise to another) was rigorously tested. The testing stages formed a consecutive development of communication between different groups and facilitated deepening levels of cooperation among them. The stages illustrate a growing dependence on the evolving communicative medium by all participants up to the final stage, that of 'hybrid repertoires' when the only effective mean of efficient communication among the actors about the project was the set of joined repertoires. As financial risk management gradually became the universal means of communication among market participants, it also gradually transformed from a descriptive language to a constitutive one. Namely, there was simply no other way to assess risk and act according to that assessment without using the risk management language. At that stage, discussed in the last section of this paper, the dependence on the boundary object was so profound that the communicative and organizational efficacy of the risk management system were as important as the accuracy and reliability of the predictions it provided.

Before we analyze in detail the history of financial risk management in derivative markets, it will be helpful to characterize generally the different forces that were at play. Much of the historical period described in the paper is characterized by rapid growth in the popularity of exchange-traded stock options and in growing volumes of options trading. This growth was related to three processes. First, as volumes grew, trading practices and techniques changed in order to accommodate the increasing number of trading orders. In addition, the complexity of trading practices grew and the division of labour within the trading firms gradually became more pronounced and the different roles more specialized. Second, the risk- and price-evaluation methods used in trading were adapted to the more varied trading environment and became increasingly dependent on mathematical risk management. Third, the markets' infrastructure, and especially options clearinghouses, having to cope with both growth in volumes and increasing complexity in trading practices turned to mathematical pricing models for a solution. Table 1 describes the three facets of the period:

\section{Table 1: Periods in the history of financial risk management in options} exchanges

\begin{tabular}{llll} 
& $\begin{array}{l}\text { Trading /clearing } \\
\text { Practices }\end{array}$ & $\begin{array}{l}\text { Risk management } \\
\text { tools }\end{array}$ & $\begin{array}{l}\text { Institutional } \\
\text { structure of the } \\
\text { Market }\end{array}$ \\
\hline $\mathbf{1 9 7 3 - \mathbf { 1 9 7 5 }}$ & $\begin{array}{l}\text { Single traders, } \\
\text { scalping }\end{array}$ & $\begin{array}{l}\text { Sheets with } \\
\text { calculated prices }\end{array}$ & $\begin{array}{l}\text { CBOE is the only } \\
\text { options exchange }\end{array}$ \\
\hline $\mathbf{1 9 7 6 - \mathbf { 1 9 8 4 }}$ & $\begin{array}{l}\text { Inter-market } \\
\text { distributed portfolios; }\end{array}$ & $\begin{array}{l}\text { Spreading, daily } \\
\text { trading strategies } \\
\text { Margins calculated } \\
\text { using strategy-based } \\
\text { method }\end{array}$ & $\begin{array}{l}\text { Options traded in } \\
\text { several exchanges }\end{array}$ \\
& $\begin{array}{l}\text { Index tracking; } \\
\text { dynamic portfolio } \\
\text { insurance }\end{array}$ & $\begin{array}{l}\text { Marging of Non- } \\
\text { Equity Options } \\
\text { (NEO) calculated } \\
\text { using pricing model }\end{array}$ & \\
\hline $\mathbf{1 9 8 5 - \mathbf { 1 9 8 7 }}$ & &
\end{tabular}




\begin{tabular}{lll}
\hline October 1987 & $\begin{array}{l}\text { Under extreme volatility, Black-Scholes- } \\
\text { Merton-based applications are not accurate }\end{array}$ & $\begin{array}{l}\text { International order } \\
\text { books for derivatives }\end{array}$ \\
\hline $\mathbf{1 9 8 8 - 1 9 9 4}$ & Testing of model- & Theoretical prices \\
& based application for & and volatility on \\
& net capital & CBOE display \\
& requirements & boards \\
& (TIMS), approved by & \\
& SEC in 1994 & \\
\hline
\end{tabular}

\section{Risk assessment practices in early CBOE}

Brief explanations about financial options and the mathematical model used in options market (the Black-Scholes-Merton model) are necessary before presenting the historical findings. Options give their buyers the right, but not the obligation, to buy ("call option") or to sell ("put option") a certain asset at a set price on (or before) a given future date. Sellers of options take upon themselves the obligation to sell the assets at the set price or to buy them at a set price if the buyers decide to exercise the options. By buying a put option, a trader can protect him/herself from the possibility of prices dropping. Similarly, by selling options, different traders can be paid for taking upon themselves other traders' risks.

Without delving too deeply into the theoretical background of the Black-ScholesMerton model, a few points about it should be explained. It is a mathematical pricing model that can be used to predict options contracts' prices (Black and Scholes 1972; Black and Scholes 1973; Merton 1973). Alternatively, knowing the present price of a contract, one could use the formula to evaluate how risky a certain market position is. ${ }^{3}$ This is how the Black-Scholes-Merton model is used to estimate the prices of options. First, the amount of option and stock that compose a risk-free portfolio is calculated. Then, since the cash flow generated by this portfolio is identical to the one generated by an interest-bearing account, it is assumed that the prices of the two equal portfolios would also be equal. This procedure produces two important results. First, the formula returns the estimated price of an option contract at a certain date prior to expiry. Second, the calculation returns a ratio between stock and option that would create a risk-free portfolio. However, because of the continual price change, that ratio had to be recalculated repeatedly and, in order to maintain it, stock had to be bought or sold in infinitesimally short intervals whilst incurring transaction costs.

\section{The use of Black's sheets}

As mentioned above, historical circumstances made options pricing theory and exchange-based option trading closely linked. The Chicago Board Options

\footnotetext{
3 The model is based on the 'no arbitrage' hypothesis which assumes that prices in markets react instantly to new information that reaches them and therefore risk-free profit-making opportunities are virtually non-existent. In other words, no risk-free arbitrage is possible in financial markets. If the 'no arbitrage' assumption were put in a complete market setting, then an asset (or a combination of assets - a portfolio) that bears no risk to its holder (risk-free) would have to generate the same cash flow as an interest bearing account (which is another risk-free instrument). That result also means that the prices of the elements composing a risk-free portfolio could be discovered by comparing them with the expected yield of cash invested in a risk-free interestbearing account.
} 
Exchange (CBOE) started trading options based on 16 'blue-chip' stocks in April 1973, a few weeks before the Black-Scholes-Merton model was first published. Fischer Black, one of the developers of the model, started in 1975 a weekly subscription service selling sheets containing options' calculated prices for that week. This first application of the options pricing model was using a 'case by case' approach. By calculating a bare-bones Black-Scholes-Merton formula, one option contract's price or hedging ratio was predicted.

Table 2: Sample of data from Black's sheets*.

Strike Price: 50.40

Date of expiration

\begin{tabular}{|l|l|l|}
\hline $\begin{array}{l}\text { Last Friday of } \\
\text { July } 1976\end{array}$ & $\begin{array}{l}\text { Last Friday of } \\
\text { October 1976 }\end{array}$ & $\begin{array}{l}\text { Last Friday of } \\
\text { January 1977 }\end{array}$ \\
\hline$\$ 9.26$ & $\$ 9.53$ & $\$ 10.00$ \\
\hline
\end{tabular}

*The sample shows the prices predicted for the $4^{\text {th }}$ of June 1976 for call options written on stocks of US Steel Corporations. Prices were calculated on $25^{\text {th }}$ of May 1976.

CBOE was established by a group originating from Chicago Board of Trade (CBOT), the city's well-established agricultural commodities exchange (MacKenzie, 2000). In its early days, most of CBOE's traders came from CBOT $\left(\mathrm{R}^{4}, 2000\right)$. Unsurprisingly, the practice that evolved around Black's sheets was based on one of the common trading technique in the Chicago commodities markets - scalping. Scalping was a very basic 'buy low - sell high' tactic, executed many times during a typical trading day and utilizing minute fluctuations in prices. With scalping as the main trading technique, the mode of operation of this first risk assessment/trading application was as follows: traders calculated the theoretical value of one option contract, compared it to the contract's market price, and then decided whether it was profitable to buy or sell. Hence, trading while using Black's sheets can be described as model-aided scalping. The sheets supplied pinpointed information to the trader: the model-calculated price of a specific option contract on a specific date.

The information provided by the sheets was particularly useful for single traders operating on their own for a number of reasons. First, most of them had relatively small portfolios ${ }^{5}$, so they could easily estimate the implication on the entire portfolio of selling or buying this or that contract. Second, the part of the portfolio that was traded on CBOE (i.e., the options ${ }^{6}$ ) was concentrated on the trading pits in which the particular trader specialised. This focused approach made the use of the sheets easy from yet another aspect: the typical trader had to purchase sheets only for a small number of options' series, and had fewer pieces of paper to carry and manage in the crowded trading pits (J, 2000). ${ }^{7}$ Third, because most trading firms had only very small numbers of traders, of which typically only one was the senior partner, it was relatively easy to execute single-handed, portfolio-wide changes. For example, a small firm could make changes to their positions during the trading day in order to utilize price discrepancies between market prices and prices calculated in the sheet (Securities and Exchange Commission 1978: 130-6).

\footnotetext{
4 As several interviewees requested anonymity, they will be identified by a single letter. All quotes were authorized by the interviewees.

5 Portfolios containing relatively small number of options and stock positions (usually less then a hundred), but not necessarily a small amount of money invested in each position.

6 Stocks were traded in a stock exchange. During the period discussed in this paper, stocks and underlying options were typically traded in the New York Stock Exchange.

$7 \mathrm{~J}$ was a trader in CBOE from the early '70s onwards. In the late '90s he headed the exchange.
} 
In many cases, it only took a decision and a quick word between the partner traders to change positions in order to take advantage of a price discrepancy. During this period, roughly between 1973 and 1977, the reliance on the mathematical model as a trading aid was far from being unanimous. A significant number of traders who were veterans of the commodities market from which CBOE emerged believed that there was no substitution to the sharp senses and instincts that one developed in the trading pits. Indeed, some trades even believed that using sheets was a form of 'cheating' or an unmanly behaviour (MacKenzie \& Millo 2003). Nevertheless, the popularity of Black's sheets was considerable and, as options trading changed, opponents of the model gradually became a minority.

\section{Comprehensive risk management systems}

\section{Spreading}

Between 1973 and 1977, volumes in options exchanges grew by more than 500\% and the number of firms doubled (Securities and Exchange Commission 1978). As the markets for options flourished, so did the trading firms, which no longer employed one or two floor traders, but up to a dozen, along with a similar number of clerks, runners and back-office employees (E, 2000). In the larger trading firms, portfolio-wide changes could no longer be performed by a single trader. Although scalping aided by sheets was still a possible trading strategy, coordination among the traders became increasingly important so that the different positions' trading orders would not undermine each other. Gradually, bare-boned Black-Scholes-Merton-based applications, like the pre-calculated sheets, ceased to serve as devices in their own right and were incorporated into larger portfolio management systems. One of the first steps in this direction was a Black-Scholes-Merton-based trading practice known as 'spreading' (Securities and Exchange Commission 1978). Spreading was a basket term for a variety of planning techniques that were all based on the same principle: finding probable discrepancies between options' market prices and between their model-generated prices (this was done by computer-programmed calculations of many separate positions) and then using those results to devise a daily trading strategy.

The main difference between the sheets and 'spreading' lay in the organizational setting of the different methods. Usually, traders who used Black's sheets were able to take advantage of the market/model price discrepancies only if they noticed them during the trading day (J, 2000). On the other hand, spreading was planned before the beginning of the trading day at the trading firm's back office, not necessarily by traders themselves. Thus, at the beginning of the day, a trader would enter the trading floor, having seen the day's risk map for the portfolio they was trading and thus knowing which options were 'overpriced' and which were 'underpriced', according to the model. The daily trading strategy was tailored with respect to these predictions. Another difference lay in the nature of information that the trades received from the methodologies. Unlike the immediate and highly specific information that was provided by the sheets, the typical results of a spreading procedure were broader guidelines that stated recommended ranges for buying and selling. 
Spreading, apart from automating the actual position-by-position calculations, also created a new stage in the options' trading design: the computer-generated trading day estimates provided market participants with a conceptual and a numerical basis for discussion. Such discussions were an inherent part of the spreading procedure because the Black-Scholes-Merton calculations, on their own, did not produce definite sets of instructions for the following trading day. Instead, the results were discussed alongside other information, risks and opportunities were evaluated and an overall picture of the trading day was generated. This lead to the design of a recommended daily trading strategy. Therefore, spreading marked an important step in the unfolding of the technosocial process in which Black-Scholes-Merton-based applications gained appreciation for their communicative value and gradually transformed from risk assessment to risk management. Spreading methodologies enabled trading firms to express risks in accessible terms and to construct a clear picture of potential market situations and possible reactions. These characteristics were indispensable for discussion of risks and for decision-making and became the cornerstone of financial risk management model-based applications.

In the early days of option trading in CBOE, much as in the commodities world from which it sprang, trading was an expertise that was learned through apprenticeship. A trader would typically start her/his career as a floor runner ${ }^{8}$, a job that they would do for 1-2 years before possibly becoming a junior partner and perform trades independently. Yet, even as a junior trader, the partner would generally seek advice from the more senior partners. In firms where daily trading plans were designed with the aid of a spreading application, a new factor was added to the decision making process - the input provided by the application. For example, an enthusiastic young trader could employ a model-generated result as a source of support for a proposed daring trading strategy, frequently against the advice of a senior partner. Similarly, referring to a prediction offered by the application could bridge over the differences between opinions about the route that should be taken in a certain situation. The information coming from the application became a computer-generated boundary object - a reference point whose communicative value was commonly accepted and was therefore available for 'recruitment' by all parties in a discussion.

\section{Multi-exchange option trading}

As options became a more popular financial contract, option trading spread from CBOE to other exchanges. By 1977, four other exchanges were also trading options: the American Stock Exchange in New York (AMEX), the Pacific Stock Exchange in San Francisco (PSE), the Philadelphia-Baltimore-Washington Stock Exchange (PBW) and the Philadelphia Stock Exchange (PHLX) (Securities and Exchange Commission 1978). Although options trading had gained significant popularity, until the mid ' 80 s the SEC did not allow for the same option contract (i.e. based on the same underlying asset) to be traded in more than one exchange and the options were distributed among the exchanges in a ballot. Thus, in order to build and maintain a diversified portfolio, traders had to execute trades in many exchanges across the country. This fact gave an advantage to the nation-wide investment firms (which had traders in all exchanges) at the expense of the local

8 A floor runner's main task was to deliver order notes to the trader from the back office and execution notes from the trader to the bookkeeper. 
firms that typically traded only in one of the exchanges. The late '70s witnessed a change in the ecology of the options traders' population. The Chicago-based firms that originated from the commodities trading markets were accompanied by big, nation-wide firms that entered options markets as an extension to their securities trading (Securities and Exchange Commission 1980).

The entrance of large investment firms did not only change the composition of traders on the trading floor; an equally significant change took place in the portfolios management practices. The large trading firms typically had huge portfolios, containing thousands of positions, distributed among four or five different exchanges, and their trading activity was conducted by a few dozen traders. When managing a portfolio of such a size, there was little sense in asking the question: 'what are the risks (and opportunities) involved in the current positions?'. There were simply too many possible answers to this question to serve as a basis for planning a strategy. ${ }^{9}$ Hence, the communicative challenge facing market participants in such an environment was two-fold. First, the highly complex information contained in the large portfolios had to be simplified so that decision-making could occur. Second, an agreed-upon communicative medium describing portfolio risks was necessary so that the various people involved in executing trading orders and operating in different cities could coordinate their actions.

Facing these organizational challenges, trading firms started to consider a new approach to portfolio management. An approach that, for the first time, managed risk directly. Instead of calculating theoretical prices for each of the positions and then summing up these results, the new approach took a hypothetical result as its starting point. In other words, the operational question of this new risk management method was: 'what if the market drops/rises by X percent tomorrow, how would that affect the portfolio?'. To answer such a question, the methodology assumed (in fact, simulated) a market movement of a certain size, say of $10 \%$, then calculated the impact that the market movement would have on each of the positions, and finally summarized the results so as to come up with the overall implication on the portfolio. In essence, the systems simulated possible future market scenarios by using results coming from the Black-Scholes-Merton model. $^{10}$

Scenario-simulating systems added a new dimension to the communicative function of the boundary objects. The applications not only created a reference point for the market participants, but also represented the complex market picture in a clear and coherent way. In fact, the communicative efficiency of this new risk management methodology was such that even the information still originating directly from the markets was 'mediated' by model-generated results. For example, in order to simplify the positions, these were presented as a percentage of the previous day's gain/loss predictions and not as absolute numbers (Securities and Exchange Commission 1986). Results from the scenario-simulating systems

\footnotetext{
9 Large investment companies managed multi-exchange portfolios before exchange-traded options appeared. Yet, the level of coordination necessary in options trading was much higher than in stock trading as the vast majority of options positions were composite: composed of stock positions and one or more option positions that were bought and sold simultaneously, frequently at different exchanges.

10 The general principle behind this methodology was later incorporated into Value at Risk (VaR), one of today's leading financial risk management techniques.
} 
became an indispensable mediating step between the market and its participants. When using scenario-simulating systems to design their trading strategy, market participants were no longer confined to concrete results from the market but were able to resort to predicted future situations.

Moreover, scenario-simulating risk management systems transformed the communicative possibilities of market participants. Whereas the use of spreading merely enhanced the ability of traders to communicate their ideas about trading strategy, the new type of applications became the tools with which such ideas were generated in the first place. When spreading, a trader could only illustrate the benefits of the trading strategy she/he had already planned. In contrast, with the scenario simulating risk management systems, it became possible, even likely, to receive the initial idea about possible trading opportunity by examining the application's output. Thus, the presentation of scenario simulating technology extended the socio-technical role of financial risk management beyond the initial definition of boundary objects. For example, after the proliferation of scenario simulating applications, traders started to talk about 'buying volatility' or 'selling volatility', when increasing the relative share of options in their portfolios. That is, model-based applications indicated that risky assets of various degrees should be bought or sold in order to balance the portfolio. Scenario-simulating did not merely supply reference points for discussions; by presenting a new discourse to the management of portfolios it made the very existence of such discussions possible.

\section{Risk management away from the trading floor: Options clearing and the Black-Scholes-Merton model}

Prices and risks related to options positions were a matter of concern not only for the traders, but also for the options clearinghouse (Options Clearing Corporation $\mathrm{OCC}^{11}$ ) and for the regulator of securities markets, the American Securities and Exchange Commission (SEC). In fact, this part of the historical analysis reveals aspects of financial risk that do not relate directly to the narrow utilitymaximization assumption that is usually attributed to market participants. Moreover, it shows that financial risk management indeed played a vital role as a boundary object, not only within the trading community but among other market participants as well. The two important actors in the historical narrative, the options' clearinghouse and the SEC were not interested primarily in maximising potential profits. Instead, the two bodies were more concerned with the organizational and regulatory impacts of financial risk.

Fundamentally, an options clearinghouse ensures that the future obligations of buyers and sellers of options (which are embedded in the options contracts) are met. To prevent the risk of one of the parties not fulfilling its duties according to the contract and to ensure that the market remained liquid and trustworthy, the clearinghouse was assigned as the immediate buyer of options from the sellers and the immediate seller to buyers. ${ }^{12}$ As the 'other side' of the contracts (until expiry

11 Since OCC was the only options clearinghouse for organized exchanges at the discussed period, we refer to it as "the clearinghouse".

12 The concept of the modern options clearinghouse was developed by the CBOT team who set up the first options exchange. Indeed, the concept of a clearinghouse as an entity separate from the 
or offsetting), the options' clearinghouse was exposed to considerable risks. In order to protect against those risks, the clearinghouse collected a portion of the contracts' value as collateral, known as margin. Participants had to deposit margins when they entered into a contract, and the margins may then either decrease or increase according to daily price fluctuations.

Apart from its own margins, OCC was also responsible for the calculation and collection of another set of risk-related fees - the SEC's net capital requirements. According to the SEC's net capital rule ${ }^{13}$, traders who regularly executed transactions for others, collectively known as broker-dealers (or 'brokers') ${ }^{14}$, were required to make daily deposits of specified amounts of money, known as net capital. Unlike margins, the net capital rule's purpose was not to protect the clearinghouse, but to protect broker-dealers' customers in case their funds were inadvertently involved in risky positions held by their brokers. If such losses occurred, then the pre-deposited capital would be put towards covering them.

In the first three years of its operation, two different methods were used in the options clearinghouse for determining the amounts of margins and net capital requirements. For the clearinghouse's own margins, a premium-based method was used. That is, a fixed premium was paid regardless of the positions' components (Seligman 1982). The net capital requirements, on the other hand, were calculated using a strategy-based method. The strategy-based method of risk-evaluation was based on a set of categories that assigned various levels of risk to different financial products. For example, options were considered more risky than bonds, so the required deposit for options was larger than the one for bonds.

The fact that two separate methods were used for the evaluation of the same factor - market risk - caused uneasiness within the trading community. $\mathrm{H}$, who was a senior executive at the clearinghouse from the late ' 70 s to the mid ' 90 s, described the early years of option clearing:

At about 1977-8, OCC had a premium-based margin requirements [calculation methodology] and we were barraged with requests to convert the margining system to something like the way net capital rule worked at the time, which was strategy-based as well. The requests for the changes came from the trading community, principally, and they came in with graphs and numbers and said something like: 'My risk is limited to this; you should never charge me more than this in margins'. (H 2000)

Brokers and other traders, who had to pay both the SEC's capital requirements and the clearinghouse's margins, demanded the clearinghouse stop charging margins according to the premium-based method and to switch to the strategybased method (which was already in use in the 1975 revised net capital rule). From the traders' point of view, the premium-based method was problematic because it did not reflect the growing complexity embedded in options' positions

trading community, played an important role in the approval of the options exchange itself (R, 2000)

13 The rule to which the paper refers is the revised net capital rule from 1975. Prior to the 1975 amendments (the net capital rule was first written in 1942), brokers had to deposit a set amount of capital at the beginning of a trading day, regardless of the risk level associated with their positions (Seligman 1982).

14 The largest group of traders handling accounts of others were broker-dealers, who were registered with the SEC, although there were other groups, other than the registered brokerdealers, who were came under the definition of the net capital rule. 
and trading methods. Because options were often used to minimize risk levels, charging a flat rate for all options positions, regardless of the implied risk embedded in them, was defeating the purpose of using options altogether.

Traders were not the only ones who demanded changes in the calculation methods. Organized option trading was an emerging and highly competitive financial practice in the mid " 70 s, and each of the exchanges that traded options wanted to attract customers. Since OCC was the only options clearinghouse at the time, it faced demands from all exchanges to charge less for its services. Facing those pressures, in 1977 the clearinghouse changed its method for margin calculation from a premium-based method to strategy-based one (Securities and Exchange Commission, 1986). ${ }^{15}$ The new calculation method was seen as a positive move by both the brokers and the exchanges. However, from the clearinghouse's side, the move entailed some significant problems:

[The] strategy based approach, intuitively for OCC, would have complicated the nightly margin calculation process to such an extent that, because everybody was increasing volume on the CBOE, we were worried that we would not be able to get the exercising assignment notices and the reports out in time ${ }^{16}$, if we had to calculate margins for the entire market place. What they wanted you to do was to take large accounts with all sorts of positions and break them down into components, strategies, and minimize their margin requirements. Mathematically, it was an optimization problem that would have required iterative calculations. (H 2000)

Unlike the premium-based method, in which every transaction was charged a predetermined rate and hence was relatively easy to perform, the strategy-based method required a more arduous procedure. Each portfolio (typically including between 100-200 different options and stocks) had to be broken down to basic positions defined in the rule; for each of those positions a risk level ${ }^{17}$ (in the case of net capital requirements) or margin payment were determined and then the calculated amounts were summed up, producing the daily margin payment or the net capital requirement. Furthermore, because there were several possibilities for breaking down complex positions into simple ones, there also existed several alternative levels of margin payments. That meant that the clearinghouse had to perform an optimization process for each of the portfolios to determine the specific splitting of positions that would result in the minimal payment satisfying the rule. This optimization process had to be done nightly so that payments, in or out of the trader's account, could be made in the following morning for the next trading day. This placed an enormous pressure on the clearinghouse's clearing system.

Apart from the growing volumes, the increasing sophistication of option trading also made the performance of the optimization process increasingly difficult. Even before organized option exchanges existed, traders used complex strategies to utilize and amplify options' hedging and leverage abilities. After the opening of CBOE, the organized market, strategies became ever more sophisticated. For example, some strategies consisted of simultaneously buying and selling options

15 By doing so the clearinghouse followed the SEC, which had presented a strategy-based method for the calculation of net capital requirements two years earlier. 16 Exercising assignment notices informed trading firms about the amount of daily margin they were required to pay.

17 Risk levels were expressed in the form of 'haircuts' - discounts applied to the original value of the positions. The riskier the position was, the larger the haircut was. 
from the same series, but with different strike prices. By creating such positions, traders 'covered' a range of possible future stock prices at or near expiration date. In order to calculate margins and net capital requirements, portfolios had to be broken down to basic positions. The more separate strategies there were, the more conditions and rules had to be built into the computer programs that performed the actual splitting into basic positions. One of the consequences of the increased demands from the clearinghouse was that it occasionally attempted to lessen the enormous workload by 'simplifying' the strategies. Instead of following all the possible routes in order to find the minimal net capital requirements in a complex portfolio, simpler positions were chosen and portfolios were charged accordingly: .... and then you have First Options [a firm for which OCC did the clearing] who would have 800 large portfolios to clear and they [OCC] have to do it account by account. So it involves a lot of computing power. They would just say: 'We're not going to do that one. We'll just ignore that strategy because it involves six more permutations.'... And the market maker [trader] will get angry or would question them and say: 'Look. If I' $m$ doing it then my real risk is that and you're charging me for this." (M 2001)

Such disputes were often not resolved between the clearinghouse and the traders. The CBOE (being a self-regulatory organization ${ }^{19}$ ) was often called in to intervene and mediate. As options strategies became more complex, such disputes broke more often and this, in turn, added yet another burden to the Market Regulation Division.

The clearinghouse's problems were reflected, in part, by the SEC. Each time a new strategy was presented by traders, SEC had to examine it according to the net capital requirements to see if the proposed strategy complied with the rule's definitions. During the mid to late '70s, many of the major American broker firms expanded into option markets, causing portfolios' designs to get steadily more complex, and thus making the rule's maintenance work more cumbersome and time-consuming. The rapid growth in options' trading volumes created a situation in which some personnel at the division responsible for market regulation at the $\mathrm{SEC}^{20}$ spent much of their time adjusting the net capital rule to the flux of new portfolio strategies. This situation was a cause for much concern in the division, since one of the main purposes of the net capital rule's 1975 amendments was to make the determination of net capital requirements more straightforward and efficient. M describes it as:

Our role had gotten so complicated when strategies have constantly been replaced with other strategies. It has become very hard to function in that environment. No matter what you did, there would be another one [trading strategy]. (M 2001)

As a result of the trends described above, concern was developing about the discrepancy between the sophistication of portfolio-construction methods

\footnotetext{
$18 \mathrm{M}$ was a senior attorney at the SEC's division of Market Regulation from the early '70s to the mid '90s.

19 According to the American securities law, national securities exchanges and their clearinghouses are considered self-regulatory organizations. That is, some of the monitoring, supervising and rule-making functions otherwise performed by the SEC are delegated, in the case of self-regulatory organisations, to departments within the organization.

20 The division of market regulation was in charge of overseeing trading and clearing practices. As such, the division was in charge of applying the changes made in the net capital rule and also for designing, along with the self-regulatory organizations (the exchanges), new risk evaluation methods.
} 
displayed by trading firms and between the relatively crude risk-evaluation practices that were imposed by the regulator:

I would hear [complaints about clearing], but what were we going to do? I mean, that was the rule. They were the ones who wanted the complicated strategies. I wasn't the one saying: 'I want you to do these complicated strategies.' They wanted to do them. They would, obviously, then have to do the work. (M 2001)

That discrepancy was rooted in the different viewpoints the SEC and the other market participants (i.e. trading firms, the clearinghouse and the exchanges) held regarding risk management. From the regulatory point of view, risk management was intended to protect customers by collecting 'back up' funds in the case of a loss, and such money was indeed collected by the clearinghouse. Since the funds were not expected to cover fully the losses in any case, the exact amount was of little significance as long as it was above the set minimum. ${ }^{21}$ Therefore, for the SEC, a strictly exact measurement of risk was less important than the fact that a rule positively defining the collection net capital was followed. In contrast, from the traders' point of view, sophisticated portfolio strategies were critical in achieving an advantage over competitors. Hence, a relatively crude net capital rule would have undermined such purpose: there would not be much use to employ sophisticated strategies if those were treated as simple ones and incurred high net capital requirements. The aforementioned combination of factors - high volume of trades, sophisticated strategies and a lagging regulator - lead the clearinghouse in the late ' 70 s to look for alternatives for the existing margin calculation mechanism.

\section{Financial risk management and options clearing}

In the early '80s, two of CBOE's prominent trading firms (Chicago Research and Trading, and O'Connor \& Associates) were using scenario-simulating risk management systems. When $\mathrm{H}$ and his team in the OCC started to examine alternatives for the strategy-based margin calculation system, they quickly encountered the new technology:

I was going to grad school and one of my grad school teachers was also a CBOE market maker [trader] and he taught me options price theory and I started to talk to him. The idea was worth a try and we convinced the board [of the clearinghouse] that they should fund some study. [An external company] began to calculate potential theoretical values for us on a daily basis for all the options series for a one year period and internally we built this program that would calculate a margin requirement equal to the worst possible loss on a line by line basis. We ran that for a year, then we wrote another report to our margin committee. (H 2000)

The system developed by the OCC applied a similar scenario-simulating principle to the one traders used to design trading strategies for the calculation of required margins. While trading firms wanted to estimate the maximal daily loss in order to minimize it, the clearinghouse used the calculated figure as the required daily margin deposit. These two different set of uses outline the emergence of financial risk management as a boundary object. OCC and the trading firms were two different market participants and had different agendas to promote, yet both chose

21 The minimum value of net capital for registered broker-dealers (after their first year as brokerdealers) was set at $\$ 250,000$ or as $62 / 3 \%$ of the total debts (SEC 1975) 
the same technological approach to do so. This, however, was only the beginning of a more complicated historical picture. In the quote above, $\mathrm{H}$ described the beginning stages of a process that lasted more than 10 years. In the late '70s and early ' 80 s, the movement to model-based practices took place mainly within the broker firms, and the clearinghouse joined in only later. Trading firms were relatively quick to implement model-based systems for a number of reasons. First, as options markets became more competitive, innovative practices that had the potential to improve the effectiveness of trading were eagerly adopted.

Second, between 1973 and 1979, option trading was given the status of an SEC pilot programme and both $\mathrm{CBOE}$ and the clearinghouse were subject to extremely close SEC supervision. The pilot programme status meant that for every change to the trading or clearing practices, prior approval from the SEC was needed.

Trading firms were not subject to such close SEC scrutiny as OCC and CBOE and could therefore implement trading systems without receiving prior approval from the SEC.

Third, CBOE's organizational structure was also related to the elaborated implementation process of the proposed risk management systems. $\mathrm{H}$ mentioned that he needed to receive approval from CBOE's margin committee to run a feasibility study and to report to this committee. After proposals were submitted to the committees, making a decision involved political manoeuvring and lobbying to ensure majority in the committees' votes.

The clearinghouse, being a self-regulatory organization, was required to submit to the SEC proposals describing the nature of changes it made to its rules. As part of the reporting process, the clearinghouse was required to publicly request comments for the proposed changes and to report on the comments received. Between December 1985 and April 1986, proposals were submitted by the clearinghouse regarding its new margining system (Securities and Exchange Commission, 1986a; Securities and Exchange Commission, 1986b). From a strictly legal point, these rule changes were an internal matter of the clearinghouse and the public inspection process was more of a formality than a substantive procedure. However, it has to be mentioned that the SEC was extremely cautious with regard to approving new practices and rules. Therefore, from a sociological and a political point of view, the fact that the rule was not rejected indicated that the SEC implicitly accepted the use of mathematical models in regulatory risk management, although it was yet to pass judgement on its own net capital rule.

By 1986, model-based applications had developed into an effective boundary object that served both the trading community and the clearinghouse. Traders continually negotiated their margin levels with the clearinghouse. Typically, the two parties had different opinions about the levels of risks embedded in this or that position. However, because both sides agreed on the method in which risk was measured and represented, communicating the different opinions to each other became less problematic. Consequently, both the clearinghouse and traders had stakes in the promotion of the model-based financial risk management system. Traders based their co-ordinated trading activity on it and the clearinghouse found in the model-based margining system an answer to volume and complexity challenges. SEC's point of view on the applications was different. It is true that the increasingly popular options markets had brought 
about an explosive growth in trading strategies and those had to be approved by the SEC, but essentially the net capital rule system functioned properly - money was collected from brokers, and investors (as far as the SEC could judge) were given protection. While the clearinghouse and the traders were relying on modelbased applications and were eager to extend their use, the common opinion at the SEC about the application was still sceptical. Paradoxically enough, the event that helped to persuade the SEC to approve model-based applications for net capital rule calculation and join the model-based communicative community was an event in which dozens of broker firms went bankrupt - the October 1987 market crash.

\section{Risk management and the $\mathbf{1 9 8 7}$ market crash: the boundary object is put to the test}

By October 1987, risk management systems based on Black-Scholes-Merton were present in virtually all of the major broker firms' offices as well as in options clearinghouses. In fact, it would not be an exaggeration to say that Black-ScholesMerton-based ${ }^{22}$ systems were the de facto risk management standard in option markets. On Monday 19 October 1987, American financial markets experienced the worst one-day drop in asset prices since October 1929. Since stock prices dropped sharply, options (which were designed to lessen the effect of such situations) were in extremely high demand (Brady, 1988). Furthermore, because many investors were selling stocks to try to cut their losses, price volatility reached record levels. Many pieces of evidence show that between the 19th and the 22nd of October 1987 Black-Scholes-Merton-based applications did not calculate prices and volatility correctly. In fact, in a few cases it was reported that the computer systems displayed call option prices that were higher than the market price of the stock for which the option was written (M 2001). ${ }^{23}$

Although this paper does not discuss the possible theoretical reasons why the models were not reliable in October 1987, it has to be said that some of the basic premises on which the model was established were questioned, if not shaken, because of the events. Among the questionable assumptions was the validity of the hypothesis that prices followed a lognormal distribution. Based on the lognormal distribution is the assumption that the 'further' an event is from the mean, the less likely it is to occur. On the 19th of October 1987, it appeared that the assumption about the lognormal distribution of prices did not hold. For instance, events that had very low probabilities and, thus, were expected to occur very rarely (i.e. once in a few decades) happened a few times a day (Rubinstein, 1994). For many market participants it became apparent that under such extreme conditions ${ }^{24}$ model-based financial risk management was not predicting and managing risk appropriately.

22 Another pricing model, based on the same mathematical assumptions of the Black-Scholes was developed by John Cox, Stephen Ross, and Mark Rubinstein (Cox, Ross \& Rubinstein 1979; Ross 1977; Rubinstein 1994) and gained significant popularity during the time period described in this paper.

23 This last point refers directly to the materiality of the network that performed risk management: the theoretical model could have produced such an effect; it was the interaction between modelbased computerized applications and live traders that brought it about.

${ }^{24}$ For example, the NYSE dropped $21 \%$ on 19 October, its biggest one day drop since the 1920s. 
The first Black-Scholes-Merton-based risk management system was approved for the calculation of SEC's net capital requirements in 1994 (Securities and Exchange Commission 1994, 1997). The system was dubbed TIMS - Theoretical Intermarket Margining System. The SEC issued a 'no-action' letter about the use of TIMS in 1994 (Securities and Exchange Commission). The meaning of the letter was that no action would be taken against bodies that used TIMS. The final, unrestricted approval of the system was granted in 1997 (Securities and Exchange Commission). Remembering that for the better part of the ' 80 s the market regulation division of the SEC did not approve such systems, one might ask what made the SEC approve TIMS when it did. This question becomes even more pointed when we consider that between 1984 (when the margining system was first introduced to the SEC) and 1994 (when TIMS was approved), the October 1987 market break took place. Knowing only these facts, it would seem that an event like the October 1987 market crash is not likely to motivate any regulator to support model-based applications. However, the October 1987 crash and its effect on the regulatory approval of Black-Scholes-Merton-based applications should be examined according to the role that those applications were playing in the technosocial environment of financial risk management.

The problems that the Black-Scholes-Merton-based applications faced in October 1987 were given different interpretations by the different communities that were related to the events. M was an assistant director in the SEC's division of market regulation in the late ' 80 s and early ' 90 s; while in this position $M$ headed the team that examined the OCC's system that was later to be dubbed TIMS. The examination of the system took several months between 1990 and 1991, in which time the SEC and the OCC conducted comparative performance tests between TIMS and of the existing strategy-based calculation method. At the completion of the tests, it was concluded that TIMS provided more reliable and accurate results than those produced by the strategy-based system. That is, TIMS predicted daily gain/loss amounts that were closer to the actual market results than the ones determined by the strategy-based system. However, the test period was a time of relative calm in the markets and so TIMS was not tested during periods of extreme volatility such as those that existed in October 1987. The results meant that under ordinary market conditions TIMS would provide appropriate amounts of net capital, but what would happen in times of extreme market conditions? The SEC's answer to this question was simple:

[TIMS] is good for business purposes. Obviously, a businessman should know what his risk is from day to day. He should also have an idea of what the worst thing that could happen to him, more or less. [I]n the ordinary circumstance, not much capital is needed from day to day. You only need it in stress times. Stress times don't occur that frequently. So the model is always wrong! Because it will not give that stress capital. (M 2001)

$\mathrm{M}$, like many other market participants was aware of the fact that under extreme conditions Black-Scholes-Merton-based applications did not provide accurate results. Equally, the SEC's staff was aware of the fact that virtually all of the market participants used similar systems. From a regulative point of view, it was more important to approve a system that was acceptable by all market participants (albeit unreliable under infrequent extreme conditions) than to have a system (strategy-based rules) that was resented by most of the market participants. ${ }^{25}$ This

25 This duality brings to mind Bloor's analysis (Bloor, 1978) of the reactions to social anomaly (comparing Imré Lakatos' and Mary Douglas' approaches). 
argument is rooted deeply in the SEC's regulative worldview and, in particular, the intention behind the net capital rule. The rule was designed to protect customers from the possible adverse consequences of positions they did not explicitly intend to hold. That is, if a broker constructed risky positions using customer's money without the direct intention of the customers and the positions resulted in a loss, the customers were entitled to compensation. However, in times of extreme volatility, when prices in the markets as a whole fluctuate wildly, even conservative positions could be risky. In other words, the net capital rule was not designed to protect market participants from events of the type that occurred in October 1987. Therefore, from this perspective it was of little significance that the model used in the rule was inaccurate when such events happened.

When the SEC tested TIMS in the early '90s, Black-Scholes-Merton-based applications had already served as the agreed-upon communicative and organizational basis for option trading and for the calculation of margins by the clearinghouse. The regulatory approval of TIMS, like the approval given to CBOE in the early 70s, indicated not only that the preferences of the SEC regarding options markets changed, but also that a more fundamental change took place. The dominance of model-related practices in the options market environment had a significant impact on the SEC's perspective of the markets. In particular, the concept of the 'common businessman' was influenced by the awareness that the model had become the common language in the market. When M, the SEC's senior employee, mentioned that 'a businessman should know what his risk is from day to day', he did not merely make a normative conviction that was based on the rules and the regulations of the SEC, but one that draws its power from a more general set of values. That is, market participants should know what risks they are facing every day because this is the optimal way for action in markets to be conducted - 'it is good for business purposes'. In other words, the use of model-based tools and practices no longer represented only the interests of one group of market participants or another. By this stage, model-based risk management had became a social and technological fact, part of the taken-forgranted reality of options markets.

The suggestion that TIMS, like other Black-Scholes-Merton-based applications, was more important for the organizational and social role it played in the markets than for its accuracy is potentially strengthened by yet another finding. Following the unreliable results that the Black-Scholes-Merton model produced under the extreme volatility of 1987, in the early ' 90 s OCC developed a version of TIMS that did not depend on the Black-Scholes-Merton model's lognormal random walk (Hinkes, personal communication). In this newer system, OCC made use of another set of statistical distributions, the stable Lévy distributions with infinite variance, in which extreme events like the ones of October 1987 are far more likely to occur than on the system based on the lognormal distribution. The margining system based on the stable Lévy distribution has the virtue that sudden increases in price volatility, because they are 'expected' by the distribution, do not lead to sudden, and large increases in margin demands. This version of TIMS (like the NEO system in the mid ' 80 s) is used for the calculating of OCC's own margins and therefore did not require a regulatory approval of the SEC. Nevertheless, as of late 2002, the SEC's own net capital requirements were still calculated according to the Black-Scholes-Merton-based system. As the historical narrative presented so far shows, from the SEC's regulatory perspective it is more beneficial to help to maintain and preserve institutionalized market practices that 
constitute a successful communicative network than to replace them with new practices, albeit those being arguably more accurate and valid.

\section{Conclusion}

The paper analyzed the emergence of financial risk management in derivatives markets, by exploring how options markets developed gradually into a heterogeneous techno-social network; a network in which computerized risk management systems played a pivotal role. The development of ties that constituted the market network was related to the development of an organizational communicative layer among the actors. As the findings show, the evolution of the network connections led to the organizational and technological infrastructure of the market becoming dependent on model-based applications. As risk management gradually became the standard descriptive and analytical language among market participants, the constitutive power of the communicative layer increased substantially. By the early ' 80 s, options markets had become a heterogeneous techno-social network in which there existed no other method to assess risk and act according to the assessments - other than using model-based risk management 'language'. At that stage, the dependence on the institutionalized financial risk management was so profound that the communicative and organizational benefits of the procedures became equally important to the reliability and accuracy of the mathematical model on which the risk management was based.

The main analytical tool used in the paper was the concept of boundary objects. The case analyzed indicated that financial risk management, with its universal 'risk language', had turned into an effective form of mediating representation that accommodated conflicting organizational demands. The question that may now arise concerns the ability to draw conclusions that are more general from this case. That is, should we expect to find such boundary objects in the histories of other risk management systems? This paper, on its own, cannot provide a sufficient answer to this question. The co-evolution of modern, organized options markets and financial risk management and the formation of the latter as a boundary object is a result of a unique historical set of circumstances that created, in effect, a natural laboratory. The derivative market and the mathematical model describing the contracts traded in that market (and on the basis of which the particular risk management methodology evolved) came about almost simultaneously. This historical coincidence enables us to frame explicitly and accurately the potential causal scope of the interactions among the actors that took part in the creation of financial risk management. Consequently, this allows us to draw conclusions about the reasons behind the popularity of the methodology and about the nature of its accuracy. Sadly, such conditions are impossible to replicate and very seldom occur naturally. However, this does not mean that boundary objects evolved only in this case. Indeed, what this case study shows us (and this is a potential way to generalize from it) is that risk management, by becoming an effective boundary object, turned into the common language of the market. Moreover, perhaps, to assess the potential future success of a risk management methodology we should examine not only its predictive abilities, but equally (and perhaps even more so), we should pay attention to the nature of communication that the methodology encourages and the types of organizational and inter-organizational contacts that evolve as a result. 
The paper focused primarily on the history of Black-Scholes-Merton-based financial risk management and on its ascendance into the dominant position it currently holds. Yet, as mentioned in the paper, in the early years of options trading, the Black-Scholes-Merton model faced considerable resistance. The different trading schools practiced different calculation methodologies that, at least at that stage, competed with the Black-Scholes-Merton model. Considering this fact in light of the historical analysis above, the following question can be asked: what are the reasons for the success of Black-Scholes-Merton over the other models? To answer this question, it is important to see when exactly, and for what reasons, the different risk management models started following divergent historical paths. In the early '70s, both the Black-Scholes-Merton application (Black's sheets) and its competitors were all risk management methodologies that suited the individual trader. Yet, being a mathematical formula (unlike its competitors), the Black-Scholes-Merton model was incorporated easily into computerized systems, which gradually became the communicative and managerial backbone of trading systems in the changing market environment. The other methodologies, which were qualitative in nature, were not incorporated into the socio-technical network that became financial risk management and remained methodologies for the individual trader. This brief comment is intended to highlight a potentially promising future direction of study within this evolving field. 


\section{References}

Abolafia, M. Y. (1996). Making Markets: Opportunism and Restraint in Wall Street. Cambridge, MA., Harvard Univ. Press.

Baker, Wayne E. (1984a). "The Social Structure of a National Securities Market." American Journal of Sociology 89:775-811.

Baker, Wayne E. (1984b). "Floor Trading and Crowd Dynamics." Pp. 107-128 in The Social Dynamics of Financial Markets, edited by Patricia A. Adler and Peter Adler. Greenwich, Conn.: JAI Press.

Bank of International Settlements. (2007). BIS Quarterly Review, June 2007 (http://www.bis.org/publ/qtrpdf/r_qt0706.pdf)

Beckert, J. (1996). "What is Sociological about Economic Sociology? Uncertainty and the Embeddedness of Economic Action." Theory and Society 25 : 803-840.

Beckert, J. (1999). “Agency, Entrepreneurs, and Institutional Change. The Role of Strategic Choice and Institutionalised Practices in Organisations." Organisation Studies $20: 777-799$.

Bernstein, P. L. (1992). Capital Ideas - The improbable origins of modern Wall Street. London, The Free Press.

—. (1996). Against the Gods - The remarkable story of risk. New York: John Wiley and sons, Inc.

Beunza, D. and D. Stark. (2004). "Tools of the Trade: The Socio-technology of Arbitrage in a Wall Street Trading Room." Industrial and Corporate Change 13(2): 369-400.

Black, F. and M. Scholes (1972). "The valuation of option contracts and a test of market efficiency." Journal of Finance 27 : 399-417.

Black, F. and M. Scholes (1973. "The Pricing of Options and Corporate Liabilities.” Journal of political economy 18 March-April: 637-54.

Bloor, David. (1978). "Polyhedra and The Abominations of Leviticus." The British Journal for The History of Science 11:245-272.

Brady, N. (1988). Report of the Presidential Task Force on Market Mechanisms. Washington, D.C.

Bowker, G. C. and S. L. Star (1999). Sorting things out : classification and its consequences. Cambridge, Mass. ; London, MIT Press.

Knorr-Cetina and K. U. Bruegger (2002). "Global Microstructures: The Virtual Societies of Financial Markets." American Journal of Sociology: 107-4. 
Callon, M. (1999). "Some Element of a Sociology of Translation - Domestication of the Scallops and the Fishermen of St. Brieuc Bay". The Science Studies Reader . edited by M. Biagioli. Routledge, London: 67-83.

Cox, J., Stephen Ross, and Mark Rubinstein. (1979). "Option Pricing: A Simplified Approach." Journal of Financial Economics 7:229-236.

Dale, Richard. (1997). Risk and Regulation in Global Securities Markets . Chichester: John Wiley \& Sons.

Darrat, A. F. and M. Zhong (2001). "On Testing the Random Walk Hypothesis: A Model-Comparison Approach.” The Financial Review 35 August 2000.

Duncker, E., and Disco, N. (1998). "Meaningful Boundaries: Symbolic representation in heterogeneous projects". In Getting new technologies together, studies in making socio-technical order (N. Disco and B. v. d. Meulen, Eds.). de Gruyter, Berlin.

Duncker, E. (2001). Symbolic Communication in Multidisciplinary Cooperations. Science, Technology \& Human Values 26, 349-386.

Galison, Peter. (1997). Image and logic : a material culture of microphysics. London: University of Chicago Press.

Granovetter, M. (1985). "Economic Action and Social Structure: The problem of Embeddedness." American Journal of Sociology 91: 481-510.

Granovetter, M. (1992). "Economic Institution as Social constructions: A Framework for Analysis.” Acta Sociologica 35: 3-11.

Izquierdo, J. (2001). "Reliability at Risk: The Supervision of Financial Models as a Case Study for Reflexive Economic Sociology." European Societies 3:69-90.

Kalthoff, H. (2005). "Practices of calculation: Economic representations and risk management." Theory, Culture and

Society 22(2): 69-97.

Kibler, N. and S. Molinari (1983). "Broker-dealers' Financial Responsibility under the Uniform Net Capital Rule". Georgetown Law Journal . 72 .

Lépinay, Vincent. (2000). "How Far Can We Go in the Mathematization of Commodities"." Paper presented in the International Workshop, Culture(s) of Financial Markets. Bielefeld, Germany.

Latour, B. (1988). "Mixing Humans and Nonhumans Together: The Sociology of a Door-closer." Social Problems 35(3): 298-310.

MacKenzie, Donald. (2001). "Physics and Finance: S-Terms and Modern Finance as a Topic for Science Studies." Science Technology and Human Values 26:115144. 
Mackenzie, D. and Y. Millo (2003). "Negotiating a Market, Performing Theory: The Historical Sociology of a Financial Derivatives Exchange." American Journal of Sociology 109(1): 107-145.

MacKenzie, D. (2006). An Engine, Not a Camera: How Financial Models Shape Markets. London: The MIT Press.

MacKenzie, D. (forthcoming). Material Markets: Facts, Technologies, Politics. Oxford: Oxford University Press

Merton, Robert C. (1973). "Theory of Rational Option Pricing." Bell Journal of Economics and Management Science 4:141-83.

Miller, P. and T. O'Leary (2007). "Mediating instruments and making markets: Capital budgeting, science and the economy." Accounting, Organizations and Society 32(7-8): 701-734.

Millo, Y. (2007). "Making Things Deliverable: The Origins of Index-Based Derivatives". Market Devices. M. Callon, Y. Millo and F. Muniesa (eds.) . Oxford, Blackwell.

Merton, Robert C. (1973). "Theory of Rational Option Pricing." Bell Journal of Economics and Management Science 4:141-83.

Muniesa, Fabian. 2000. "Performing Prices: The Case of Price Discovery Automation in the Financial Markets." Pp. 289-312 in Okünomie und Gesellschaft, edited by Herbert Kalthoff and Richard et al Rottenburg. Marburg: Metropolis.

Polanyi, K. and R. M. MacIver (1957). The great transformation. Boston, GowerBeacon Press.

Ross, S. (1977). "The Capital asset pricing model CAPM, short-sale restrictions and related issues." Journal of Finance 32:177-84.

Rubinstein, Mark. (1994). "Implied Binomial Trees." Journal of Finance 69:771818.

Securities and Exchange Commission, (1975). Securities Exchange Act of 1934, Rule 15c3-1. Code of Federal Regulations . 17 part 240 .

-. (1978). The SEC Speaks.

-. (1978). "Report of the Special Study of The Options Markets to the Securities and Exchange Commission." Securities and Exchange Commission, Washington, D.C.

—. (1980). The SEC Speaks.

—. (1986). Self-Regulatory Organizations; Options Clearing Corp.; Order Approving Proposed Rule Change. Release No. 34-23167; File No. SR-OCC-8521. 51 FR 16127 . 
-. (1986). Self-Regulatory Organizations; Options Clearing Corp.; Proposed Rule Change. Release No. 34-22844; File No. SR-OCC-85-21 . 51 FR 4257.

—. (1986a). "Self-Regulatory Organizations; Options Clearing Corp.; Order Approving Proposed Rule Change." in Release No. 34-23167; File No. SR-OCC85-21, vol. 51 FR 16127.

—. (1986b). "Self-Regulatory Organizations; Options Clearing Corp.; Proposed Rule Change." in Release No. 34-22844; File No. SR-OCC-85-21, vol. 51 FR 4257.

—. (1994) Release No. 33761 ("Proposing Release"). Washington, DC.

—. (1997) "Release No. 34-38248; File No. S7-7-94." Washington, DC.

Seligman, Joel. (1982). The Transformation of Wall Street - A History of the Securities and Exchange Commission and Modern Finance. Boston: Houghton Mifflin.

-. (1985). The SEC and the Future of Finance . New York: Preager.

Steinherr, A. (1998). Derivatives The Wild Beast of Finance . New York, John Wiley \& Sons.

Uzzi, B. (1996). "Embededdness and Economic Performance: The Network Effect." American Sociological Review 61:674-698.

Uzzi, B. and James Gillespie. (2002). "Knowledge Spillover in Corporate Financing Networks: Embeddedness, Network Transitivity and Trade Credit Performance," Strategic Management Journal, 23:595-618.

Uzzi, B. and Ryon Lancaster (2003). " Relational Embeddedness and Learning: The Case of Bank Loan Managers and Their Clients" Management Science, 49: 383-399.

Zuckerman, E. W. (1999). "The Categorical Imperative: Securities Analysts and the Illegitimacy Discount." American Journal of Sociology, 104: 1398-1438. 